\title{
FORMULATION OF STIRRED PROBIOTIC FRUIT YOGURT TO BOOST IMMUNITY
}

\author{
Poornima Jeyasekaran ${ }^{1 *}$, M. Deepa ${ }^{2}$
}

${ }^{1}$ Department of Food Science and Nutrition, The American College, Madurai, Tamil Nadu, India

${ }^{2}$ Department of Food Science and Nutrition, Periyar University, Salem, Tamil Nadu, India

Received - July 18, 2020; Revision - September 17, 2020; Accepted - December 08, 2020

Available Online March 25, 2021

DOI: http://dx.doi.org/10.18006/2021.9(Spl-1-GCSGD_2020).S169.S175

\section{KEYWORDS}

Stirred yogurt

Probiotic drink

Passion fruit

\begin{abstract}
The food we eat plays a key aspect in determining our overall health and immunity. Improving our immunity during the Covid-19 pandemic is challenging for all age groups. So this study focused on formulating a ready to drink called probiotic fruit yogurt from less utilized passion fruits (Passiflora edulis), as a good option to build resilience in the body against infections and also to help the planters of Thandikudi hills, Tamil Nadu to promote their harvest into a valuable product. Passion fruits were procured and handled in a very hygienic manner. The formulation of stirred fruit yogurts was carried out in three different ratios $(10 \%, 15 \%$, and $20 \%$ pulp). These samples were standardized by sensory evaluation ( 9 points hedonic scale) and physicochemical parameters $(\mathrm{pH})$. Fruit yogurt made from $20 \%$ passion fruit pulp scored the highest value in the mean score $(8.5 \pm 0.17)$ for sensory evaluation except for texture. The $\mathrm{pH}$ value of the passion fruit yogurt was 3.5 found and it was more acidic compared to the plain yogurt value of 3.7 because of the addition of fruit pulp which was balanced by the addition of sugar/stevia. The acceptability of the stirred probiotic fruit yogurt with $20 \%$ pulp was mainly because of the flavoring compounds of the yellow passion fruit (P. edulis Sims f. flavicarpa Deg).
\end{abstract}

* Corresponding author

E-mail: poornimajeyasekaran@yahoo.co.in (Poornima Jeyasekaran)

Peer review under responsibility of Journal of Experimental Biology and Agricultural Sciences.

Production and Hosting by Horizon Publisher India [HPI] (http://www.horizonpublisherindia.in/).

All rights reserved.
All the articles published by Journal of Experimental Biology and Agricultural Sciences are licensed under a Creative Commons Attribution-NonCommercial 4.0 International License Based on a work at www.jebas.org.

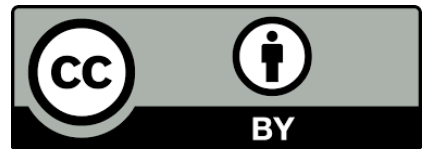




\section{Introduction}

The immune system is the complex network of cells and protein molecules that protect us from disease by surveilling our body and responding to any foreign (non-self) substances they recognize as threats, mainly infectious microbes. Our immune system has synchronized along with assorted gut flora, not only to create a defense against pathogens but also to develop some tolerance for constructive microbes (Ley et al., 2006). The importance of this interaction explores that $70-80 \%$ of the body's immune cells are found in the human gut (Abbas et al., 2017).

Probiotics are live microbes, which provided adequate amounts of health benefits to the host. The confirmation of the impact of probiotics on human health is intensifying and driving the profitable development of functional foods termed as "Probiotic food" (Sanders, 2019). Probiotics showed therapeutic potential for diseases, including several immune response-related diseases, such as allergy, eczema, viral infection, and potentiating vaccination responses (Fang \& Polk, 2011).

Yogurt is the milk product formed from the culturing of milk with bacterial cultures that contain the lactic acid-producing bacteria, Lactobacillus bulgaricus, and Streptococcus thermophilus. Furthermore, additional bacteria, such as strains of Lactobacillus and Bifidobacterium species, can be added for their health benefits (Hill et al., 2014).

Passion fruit (Passiflora edulis Sims f. flavicarpa Deg) grows in a perennial vine that is very vigorous in climbing. The woody vine yields round or ovoid fruits. The characteristics of the fruits are tough, smooth, and waxy with faint, fine white specks. Commonly, the rind is of two colors viz., dark purple and yellow. Fruit contains orange colored or pale pulpy juice with a large number of small, hard, pitted seeds which is either dark brown or black. The fruits are generally not used for table purpose (Sanders, 2009; Bakshi \& Iqbal, 2019).

A combination of yogurt and fruit intake could provide highquality protein, important fatty acids, a mixture of vitamins and minerals. This fruit yogurt bestows as both probiotic and prebiotic can to exert synergistic effects on health (Kailasapathy \& Milchwissenschaft, 1998).

Improved probiotic viability was noted in fruit supplemented yogurt than plain yogurt due to fast consumption of phenolic compounds and organic acids such as citric acid by probiotic cultures. The inclusion of probiotic cultures and fruits in yogurt is recommended for enhancing the functional properties of traditional or home-made yogurt (Surajit, 2019). The current study was conducted to evaluate the sensory characteristics and physicochemical parameters of yogurt made from passion fruit.

\section{Materials and Methods}

\subsection{Sample collection}

A fresh pack of standardized milk was collected for the preparation of a thick yogurt formation because the addition of fruit pulp would dilute the stirred yogurt. Fully ripened yellow passion fruit was collected from the planter of Thandikudi hills - a Village in Kodaikanal Block in Dindigul District of Tamil Nadu State in India. The fruits were washed well and cut into two halves. Then the pulp along with the seeds was scooped out.

\subsection{Formulation of Fruit yogurt}

Milk sample was collected and boiled; this was followed by the cool down to a temperature of $37-41^{\circ} \mathrm{C}$. Further, two spoons of the home-made yogurt culture were added and stir well. This mixture was covered and incubates in a warm place for 5-7 hours. Fruit pulp with seeds was added to the Yogurt and blended thoroughly till all the firm curd is broken down. The mixture was refrigerated at $0-5^{\circ} \mathrm{C}$ and this probiotic fruit yogurt can be used for 3 days of opening. The detailed procedure of probiotic fruit yogurt formulation is as below.

Standardized Milk (4.5\% fat, 8.5\% SNF)

$\downarrow$

Heated to $90^{\circ} \mathrm{C} / 10 \mathrm{~min}$

$\downarrow$

Inoculation with culture (Probiotic culture from home-made starter@2\%)

$\downarrow$

Incubation at room temperature for 5 hours

$\downarrow$

Breaking the firm curd $(120 \mathrm{ml})$ by blending for a min

$\downarrow$

Addition of Stevia or sugar

$\downarrow$

Addition of fruit pulp with seed $(10 \%, 15 \% \& 20 \%)$

$\downarrow$

Stir well

$\downarrow$

Fill in glass containers

$\downarrow$

Probiotic fruit Yogurt (Refrigeration at $0-5^{\circ} \mathrm{C}$ ) 
Table 1 Mean score of 9-point hedonic scale

\begin{tabular}{|c|c|c|c|}
\hline Quality Parameters & $10 \%$ pulp yogurt & 15\% Pulp Yogurt & $20 \%$ Pulp Yogurt \\
\hline Color and appearance & $8.5 \pm 0.11$ & $8.6 \pm 0.19$ & $8.8 \pm 0.15$ \\
\hline Flavor & $8.1 \pm 0.17$ & $8.2 \pm 0.16$ & $8.4 \pm 0.25$ \\
\hline Consistency & $8.4 \pm 0.20$ & $8.3 \pm 0.10$ & $8.0 \pm 0.23$ \\
\hline Taste & $7.8 \pm 0.21$ & $8.1 \pm 0.17$ & $8.3 \pm 0.21$ \\
\hline Overall acceptability & $8.2 \pm 0.19$ & $8.1 \pm 0.19$ & $8.5 \pm 0.17$ \\
\hline
\end{tabular}

Table 2 Nutrient Analysis per 8 ounces / 227 g

\begin{tabular}{|ccc|}
\hline Nutrients & $\begin{array}{c}\text { Fruit Yogurt } \\
\text { (Present Research) }\end{array}$ & $\begin{array}{c}\text { Commercial Yogurt } \\
\text { (USDA, 2019) }\end{array}$ \\
\hline Energy & $126 \mathrm{kcal}$ & $138 \mathrm{kcal}$ \\
\hline Fat & $5.7 \mathrm{~g}$ & $7.38 \mathrm{~g}$ \\
\hline Carbohydrates & $14.2 \mathrm{~g}$ & $10.6 \mathrm{~g}$ \\
\hline sugars & $14.2 \mathrm{~g}$ & $10.6 \mathrm{~g}$ \\
\hline Protein & $4.3 \mathrm{~g}$ & $7.88 \mathrm{~g}$ \\
\hline Sodium & $140 \mathrm{mg}$ & $104 \mathrm{mg}$ \\
\hline Calcium & $157 \mathrm{mg}$ & $275 \mathrm{mg}$ \\
\hline
\end{tabular}

\subsection{Sensory Evaluation}

The formulated stirred probiotic fruit yogurt was tested organoleptically using a 9-point hedonic scale. The primary purpose for the widespread acceptance of the 9-point hedonic scale is that its categorical nature and limited choices make it easy for both study participants and researchers to use. Its simplicity further makes the 9-point hedonic scale suitable for use by a wide range of populations without extensive training. Therefore, the primary concern of a study is measuring hedonic differences among foods, beverages, and consumer products and predicting their acceptance, the 9-point hedonic scale has proven itself to be a simple and effective measuring device (Lim, 2011).

\subsection{Nutrient Content analysis}

The nutrient analysis of the formulated $20 \%$ passion fruit pulp yogurt for the macronutrients and micronutrients followed the AOAC method 20th edition, 2016 (AOAC, 2016). The nutrients analyzed were Energy, Carbohydrate, Protein, Fat, Sodium, and Calcium.

\subsection{Characterization of Microbial Culture}

Overnight culture should be given for culture identification. One loopful of culture was taken and inoculated in peptone broth. Then after 24 hours, once confluent growth appeared, the culture was centrifuged. Taken in pellets and then sent to the biotechnology lab for identification (Dubey \& Maheshwari, 2006). BLAST analysis is used for the identification of bacteria. This procedure helps to identify the strain of the bacteria present in the formulated yogurt to prove it to be a probiotic drink.

\section{Results}

\subsection{Sensory attributes}

The formulated fruit yogurts with three different ratios of fruit pulp $(10 \%, 15 \%$, and $20 \%)$ were analyzed organoleptic evaluation and tabulated in table 1. The samples were tested for their sensory attributes by 25 Semi trained panel members. The data gathered was statistically analyzed using mean \pm standard deviation. The statistical analysis report revealed that the overall acceptability of $20 \%$ passion fruit pulp incorporation was found to be highly acceptable. Whereas the overall acceptability of $10 \%$ pulp yogurt was found to be less acceptable and $20 \%$ passion fruit pulp incorporation score high acceptability because of the good taste, excellent flavor, and better color.

Out of the three tested ratios of passion fruit pulp yogurt, the $20 \%$ pulp incorporated yogurt scored a maximum except for the consistency. To further scrutinize this finding the researcher planned to do a comparative test between the plain yogurt and $20 \%$ pulp fruit yogurt before standardizing the formulation. The results were analyzed statistically by mean and standard deviation which are graphically represented in Figure 1. The semi-trained panel members observed two aspects. One is the improved flavor from the aromatic compounds present in passion fruit pulp and the other one is the crunchy seeds that enhance the texture. 


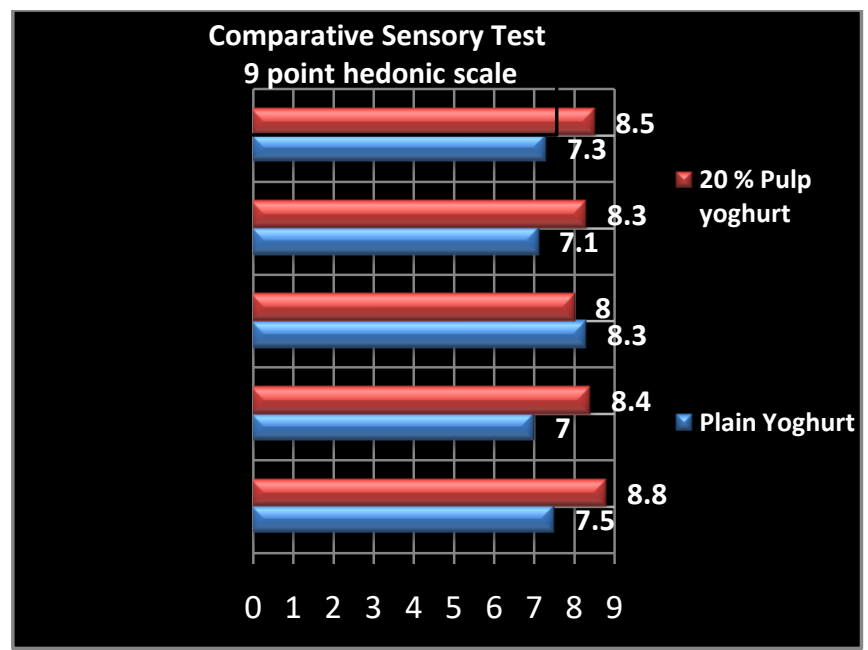

Figure 1 Comparative test graphical representation

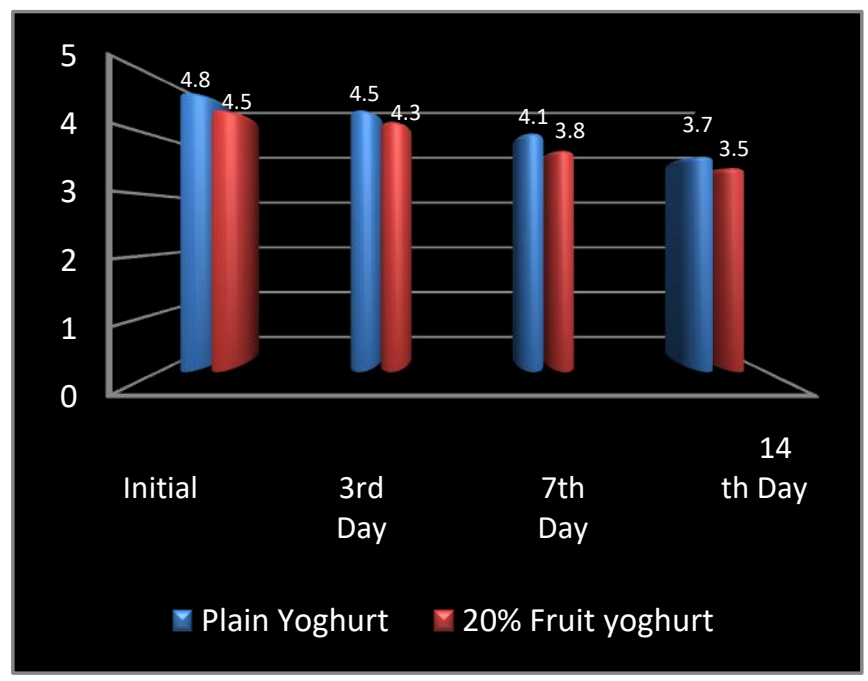

Figure $2 \mathrm{pH}$ value of yogurts
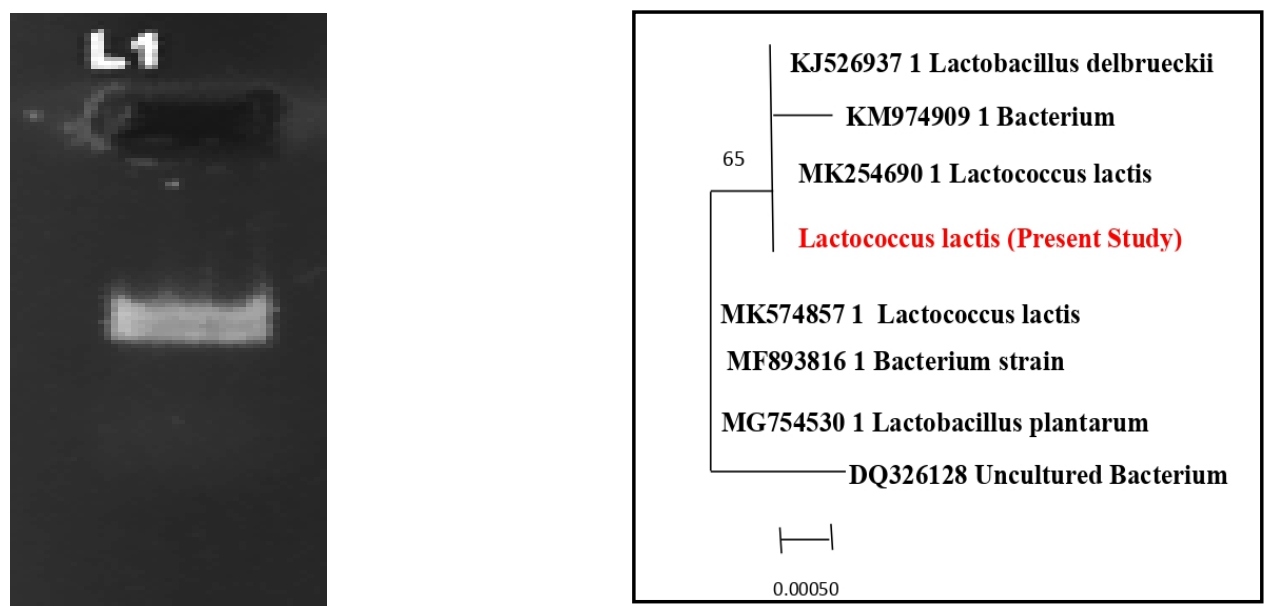

Figure 3 PCR products of 16s rRNA gene. (L1 - AM1)

Figure 4 Phylogenetic tree

Journal of Experimental Biology and Agricultural Sciences http://www.jebas.org 


\subsection{Changes in $\mathrm{pH}$ during storage}

The researcher compared the $\mathrm{pH}$ score of the plain yogurt and $20 \%$ fruit yogurt to find out the physicochemical property. The stirred yogurts were refrigerated after fermentation and fruit pulp incorporation. The value was recorded by immersing the cathode of the $\mathrm{pH}$ meter into the sample. The $\mathrm{pH}$ value is higher in the formulated product when compared to the plain yogurt. The addition of fruit pulp also alters the $\mathrm{pH}$ and acidity of yogurt. Passion fruit pulp inclusion elevates the acidity due to the acidic character of the pulp. The result is graphically represented in figure 2. The $\mathrm{pH}$ reaches the minimum value of 3.5 for fruit yogurt on the $14^{\text {th }}$ day.

\subsection{Nutrient Content}

The nutrient analysis of the formulated $20 \%$ passion fruit pulp yogurt was analyzed for the macronutrients and micronutrients based on AOAC method $20^{\text {th }}$ edition, 2016. The values obtained were tabulated below in Table 2 .

The content of calories, fat, and protein was a little lower compared to the commercial yogurt. Due to the addition of fruit pulp, there was an increase in the carbohydrates, and salt content of the stirred probiotic fruit yogurt.

\subsection{Microbial identification of bacteria report}

The prepared culture was sent for molecular identification of bacteria. Based on the higher percentage similarity against the reference species using BLAST analysis reported that the species that fermented the formulated fruit yogurt was Lactococcus lactis. Polymerase chain reactions were performed in the following temperature and timing conditions programmed in Applied Biosystems, thermal cycler.

Initial denaturation at $94{ }^{\circ} \mathrm{C}$ for 5 min., number of cycles -35 , denaturation process carried out at $94{ }^{\circ} \mathrm{C}$ for $30 \mathrm{sec}$, annealing took place at $56^{\circ} \mathrm{C}$ for $30 \mathrm{sec}$, extension passed at $72^{\circ} \mathrm{C}$ for $1 \mathrm{~min}$ and final extension process completed at $72{ }^{\circ} \mathrm{C}$ for 10 minutes for amplification.

The amplified products were tested on $1.5 \%$ agarose gel electrophoresis and the molecular weight was checked using a molecular weight marker (100bp ladder). The amplified sequences belong to $16 \mathrm{~S}$ rRNA figured in figure 3 .

The amplified sequences belong to 16S rRNA were confirmed by similarity index built in the NCBI's BLAST program. Based on the higher percentage similarity against the reference species, the species utilized in this study were assigned as L. lactis species refer to figure 4 .

\section{Discussions}

The $20 \%$ passion fruit pulp incorporated stirred yogurt scored a maximum in color and appearance, flavor, taste, and overall acceptability except for the consistency. The $\mathrm{pH}$ reaches the maximum value of 3.5 for $20 \%$ fruit yogurt on the $14^{\text {th }}$ day which is more acidic compared to plain yogurt. The nutrient content of the standardized fruit yogurt reveals that the 100 gram provides $126 \mathrm{kcal}$ of energy, $14.2 \mathrm{~g}$ carbohydrates, $4.3 \mathrm{~g}$ of protein, $5.7 \mathrm{~g}$ of fat, and $157 \mathrm{mg}$ of calcium. The microbial identification of bacteria report confirms the species that fermented the formulated fruit yogurt was L. lactis.

The human gut is populated with as many as 100 trillion cells, whose collective genome, the microbiome, is a reflection of evolutionary selection pressures acting at the level of the host and the level of the microbial cell (Ley et al., 2006). The stirred yogurt fermented with $S$. thermophilus St-Body 1 at $37^{\circ} \mathrm{C}$ for 24 hours resulted in the highest score at each sensory evaluation category (Ho-Jin et al., 2005)

The higher the casein fraction and/or the fat level, the less hiatus in the network were observed. It is also evident that the addition of whey proteins strengthens the firmness properties of low-fat yogurts when compared to characteristics of full-fat yogurt (Sonne et al., 2011). On the other hand, increasing the level of whey proteins by modification of the whey protein: casein ratio in the milk base used for yogurt production led to a major increase in granular texture perception (Kailasapathy \& Milchwissenschaft, 1998).

Nutritional facts of commercial yogurt given by the U.S. Department of Agriculture were, Calories: 138kcal, Protein: 7.88 g, Fat: 7.38g, Carbohydrates: 10.6g, Sugars: 10.6g, Calcium: $275 \mathrm{mg}$, and Sodium: $104 \mathrm{mg}$ for plain yogurt (USDA, 2019). The content of calories, fat protein, and calcium were a little lower compared to the commercial yogurt. Due to the addition of fruit pulp, there was a mild increase in the carbohydrates, sugar, and sodium content of the stirred probiotic fruit yogurt.

Synergised health benefits may be exerted when yogurt and fruits are eaten together which provides potential prebiotic and their effects (Fernandez \& Marette, 2017). The yogurts were flavored with $0.1 \%(\mathrm{wt} / \mathrm{wt})$ strawberry flavoring containing 17 odorous compounds mixed with propylene glycol. The concentrations of the aroma compounds ranged from 1.01 to $32.53 \mathrm{mg} / \mathrm{kg}$ of yogurt (Saint-Eve et al., 2006). The $\mathrm{pH}$ values arrived by the researcher for stirred fruit yogurt agree with the findings of Tesfaye \& Selvakumar (2015). The protective effects against the influenza virus were mostly derived from the cell components of L. lactis subsp. cremoris FC and its metabolites, such as exopolysaccharides. Many studies have shown that L. lactis can 
support barrier function in terms of improved mucus, production of antimicrobial peptides, and secretion of soluble immunoglobulin IgA (Martín et al., 2014)

\section{Conclusion}

The research was conducted to formulate stirred fruit yogurt which has a probiotic effect that is very important for gut health that is a good sign to boost one's immune system. Fruit yogurt made from $20 \%$ passion fruit pulp scored the highest value in the mean score $(8.5 \pm 0.17)$ for sensory evaluation except for texture and the $\mathrm{pH}$ range of the fruit yogurt (3.5) is more acidic compared to the plain yogurt (3.7) because of the addition of fruit pulp which is balanced by the addition of sugar/stevia. The acceptability of the stirred probiotic fruit yogurt with $20 \%$ pulp is mainly because of the flavoring compounds and the crunchy seeds of the yellow passion fruit. The BLAST analysis reveals that the species identified in the formulated fruit yogurt was L. lactis.

The shelf-life study to find out the growth of other microorganisms is under process. This research aims to be a corkscrew for the planters to convert their perishable produce into a valuable ready to drink convenient food with an extended shelf life and yields more profit for their produce, which also makes it available all through the year.

\section{Recommendations and suggestion}

Many locally available fruits can be converted in this way without the addition of class II preservatives thereby making them consumable for all age groups and any health conditions. Further, this study can be extended by incorporating passion fruit peel powder which is prebiotic into the stirred probiotic fruit yogurt. It can be analyzed for physicochemical characteristics and symbiotic effect.

\section{Acknowledgments}

The researcher acknowledges her heartfelt gratitude to Mr. N. Jeyasekaran, Mr. A.K. Jeya Prakash, Mr. R. Mahesh Narayanan, and Mr. G. Deepan, the Planters of Pattiveeranpatti for contributing ripened yellow Passion fruits for the study whenever needed which helped the researcher to finish the research on time.

\section{References}

Abbas AK, Lichtman AH, Pillai S (2017) Cellular andMolecular Immunology. Elsevier Health Sciences, 9th edition 11 May 2017:13

Abbas AK, Lichtman AH, Pillai S (2017) Cellular and Molecular Immunology. Elsevier Health Sciences, 9th edition 11 May 2017:13.
Tesfaye A, Selvakumar P (2015) Chemical, Microbiological and Sensory Characteristic of Date Flavored Ethiopian Curd. Journal of Pharmacological and Toxicological Investigations 1 (1): 27-34.

Dubey RC, Maheshwari DK (2006) Practical Microbiology. S. Chand Publishing, Second Edition, New Delhi, P.184.

Fang Y, Polk DB (2011) Probiotics and Immune Health. Current Opinion in Gastroenterology 27 (6): 496-501.

Hill C, Guarner F, Reid G, Gibson GR, Merenstein DJ, Pot B, Morelli L, Canani RB, Flint HJ, Salminen S, Calder PC, Sanders ME (2014) Expert consensus document. The International Scientific Association for Probiotics and Prebiotics Consensus Statement on Scope and Appropriate Use of the Term Probiotic. Nature Reviews Gastroenterology \& Hepatology 8: 506-14.

Ho-Jin K, Seung-Chun B, Je-Hyun Y (2005) Studies on the Properties of the Stirred Yogurt Manufactured by Exopolysaccharide Producing Lactic Acid Bacteria. Korean Journal for Food Science of Animal Resources 25(1): 84-91.

Kailasapathy K, Supriadi D (1998) Effect of partially replacing skim milk powder with whey protein concentrate on the sensory qualities of lactose hydrolysed acidophilus yogurt. Journal of Global 53: 385-389.

Lim J (2011) Hedonic scaling: A review of methods and theory. Food Quality and Preference 22:733-747. 10.1016/j.foodqual.2011.05.008.

Martín R, Chain F, Miquel S (2014) Effects in the use of a genetically engineered strain of Lactococcus lactis delivering in situ IL-10 as a therapy to treat low-grade colon inflammation. Human Vaccines \& Immunotherapeutics 10: 1611-21.

Sanders ME (2016) Are all yogurts 'Probiotic yogurts. California Dairy Research Foundation, Dairy Research Bulletin., August (2016). Available at https://cdrf.org/2016/08/12/yogurts-probioticyogurts/ access on 29th April 2020.

Fernandez MA, Marette A (2017) Potential Health Benefits of Combining Yogurt and Fruits Based on Their Probiotic and Prebiotic Properties. Advances in Nutrition 8 (1): 155S-164S. https://doi.org/10.3945/an.115.011114.

Bakshi P, Iqbal M (2019)Passion Fruit Plantation Guide. Avaialble at https://www.krishisandesh.com/passion-fruit-plantation-guide/ access on 29th April 2020.

Ley RE, Peterson DA, Jeffrey I (2006), Gordon Center for Genome Sciences, Washington University School of Medicine, St. Louis, MO 63108, USA. Cell 124 (4): 837-848. 
Saint-Eve A, Lévy C, Martin N, Souchon I (2006) Influence of Proteins on the Perception of Flavored Stirred Yogurts. Journal of Dairy Science 89 (3): 922-933.

Sanders ME (2009) How do we know when something called "probiotic" is really a probiotic?. A guideline for consumers and health care professionals. Functional Food Reviews 1: 3-12.

Sonne A, GroBhable K, Hinrichs J (2011) Structural properties of stirred yogurt as influenced by whey proteins. LWT- Food Science and Technology

44(10):2134-2140.

DOI:

10.1016/j.1wt.2011.05.018.

SurajitS(2019) Potentiality of Probiotic Fruit Yogurt as a Functional Food - A Review. Journal of Nutrition and Food Sciences 49(2): 3. DOI: 10.1108/NFS-05-2018-0139.

U.S. Department of Agriculture (USDA) (2019) Yogurt, plain, whole milk. Food Data Central Available at https://fdc.nal.usda.gov/fdc-app.html\#/food-

details/171284/nutrients Access on 29th April 2020. 